\title{
Plasma serotonin in patients with chronic tension headaches
}

\author{
MICHAEL ANTHONY, JAMES W LANCE \\ From the Department of Neurology, The Prince Henry and Prince of Wales Hospitals and the School of \\ Medicine, University of New South Wales, Sydney, Australia
}

SUMMARY Previous reports have suggested that platelet level of serotonin in chronic tension $\frac{\bar{C}}{5}$ headache (CTH) is lower than in normal control subjects, and that there is continuous activation of $\frac{\bar{\sigma}}{\bar{s}}$ platelets both in migraine and in CTH. In this study we compared platelet serotonin concentration in $\frac{\widehat{\otimes}}{\Omega}$ 95 patients with CTH, 166 patients with migraine and 35 normal control subjects. Mean platelet serotonin (ng/109 platelets) was 310 for the CTH group, 384 during migraine headache, 474 for $\vec{\circ}$ normal control subjects and 514 in headache-free migrainous patients. There was significant statistical difference of values between CTH patients and those of normal control subjects as well as $\vec{\omega}$ headache-free migrainous patients, but not of those of migrainous patients during headache. It is $\frac{\rho}{3}$ suggested that CTH is a low serotonin syndrome, representing one end of the spectrum of idiopathic $\frac{5}{5}$ headache, the other end being represented by migraine.

It does not appear that muscle contraction plays a significant part in tension headache, as there are many reports failing to demonstrate increased muscle tension in patients with this complaint. ${ }^{1-4}$ In fact, muscle contraction is at least as prominent in migraine as it is in tension headache. ${ }^{5-8}$ Increasing tension by $10 \mu \mathrm{V}$ in the frontalis muscle through biofeedback, for periods of 2 to 5 minutes, produced pain in patients with tension headache, during the period of contraction and 10 minutes after the contraction was stopped, whilst the control group experienced no pain at any stage. The inference of such an observation is that patients with tension headache experience pain at a lower level of nociceptive stimulation than nonheadache subjects. ${ }^{9}$

On the other hand, tension headache may on occasions encompass some migrainous features, such as nausea, a throbbing quality, or mild photophobia. There is evidence of vasodilatation in some patients with tension headache, as shown by the rapid clearance of radioisotope from neck muscles during occipital headache, ${ }^{10}$ increased severity of tension headache following inhalation of amyl nitrite, ${ }^{\text {"1 }}$ and a pulsating headache in about $50 \%$ of patients, but not in normal controls during histamine infusion. ${ }^{12}$

Address for reprint requests: Prof $\mathbf{M}$ Anthony, Department of Neurology, The Prince Henry Hospital, Little Bay, NSW 2036, Australia.

Received 17 June 1988 and in revised form 31 August 1988. Accepted 6 September 1988
The outstanding biochemical change duriri migraine headache is a fall in plasma serotonin $\widetilde{\Omega}_{\bar{Q}}$ 은 which has been considered to predispose to vasodil 2. tation, particularly of the cranial vessels, and increased perception of nociceptive stimuli by opening the pain gate..$^{14}$

Rolf et $a^{\prime s}$ have reported that platelet seroton content in patients with tension headache is signife $\overrightarrow{0}$ cantly lower than that of normal controls, and that the of changes are similar to those observed in migrainous patients during attacks of headache. If this is correct, the weight of the pendulum would tend to swing in favour of those who feel that migraine and tension headache are not necessarily separate nosological activities, but represent the two extremes of the $\stackrel{\mathbb{Q}}{2}$ spectrum of the condition now recognised as $\overline{\overrightarrow{0}}$ idiopathic headache.

The purpose of this study was to expand the observations of Rolf et al,,$^{15}$ by studying plasma levels of serotonin in a larger group of patients with tension headache and comparing them with a group of normal controls and another of migrainous subjects, both $\dot{0}$ during headache and periods of headache freedom.

\section{Patients and methods}

Ninety five patients diagnosed as suffering from chronic tension headache (CTH), were seen by the authors at their Hospital outpatient or private practice clinics, between 1983 and 1987. The diagnosis was made on the clinical charac- $N$ teristics and duration of the headache, as outlined in table 1. Only patients with daily attacks, were accepted into the 
Table 1 Diagnostic criteria of chronic tension headache of patients admitted to the study.

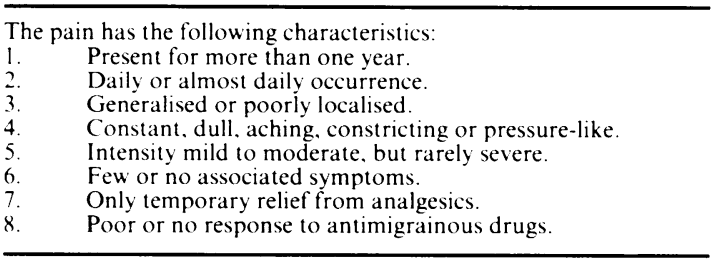

study, so as to avoid confusion with the periodic headache of migraine. Patients on preventive or analgesic medication were asked to suspend treatment for one week before the blood was collected, although most were on no treatment at all at the time of the initial interview when the procedure was performed.

Blood for estimation of plasma serotonin was collected in the morning, between 9 am and 12 midday, to minimise the effect of diurnal variations. Whole plasma serotonin was assessed fluorimetrically by a modification of the method of Crawford and Rudd. ${ }^{16}$ All estimations were performed in duplicate. If the difference between the two aliquots was greater than $5 \%$, the estimation was repeated. Plasma serotonin was expressed as $\mathrm{ng} / 10^{4}$ platelets, since they contain about $98 \%$ of serotonin in the blood. ${ }^{17}$

Comparison was made with 35 healthy (non-headache) control subjects and 166 migrainous patients, both during headache and periods of headache freedom. Statistical comparison of plasma serotonin values among the three groups of patients was made by analysis of variance, using the Student-Newman-Keyls procedure.

\section{Results}

The clinical profiles of the three groups of patients are shown in table 2. In the migraine group, about one fifth of patients $(18 \%)$ were males, whilst in that with $\mathrm{CTH}$, just over half of the group $(55 \%)$ were males.

The mean value of plasma serotonin $\left(\mathrm{ng} / 10^{9}\right.$ platelets) was 310 for the CTH group and 384 during migraine headache. In contrast, the mean value in headache-free migrainous patients was 514 and in normal controls 474 (table 3, fig). The difference between values for the group of CTH patients and normal controls, as well as headache-free migrainous subjects was statistically significant, whilst that between tension headache and migrainous patients during headache was not significant (fig). Of the 95 patients with $\mathrm{CTH}, 23$ had a mean serotonin value of $503 \mathrm{ng} / 10^{9}$ platelets, which was similar to that of normal controls and headache-free migraineurs.

\section{Discussion}

This study demonstrates that patients with CTH have mean levels of circulating plasma serotonin that are lower than those found in control non-headache subjects, in migrainous patients when headache-free
Table 2 Plasma serotonin in chronic tension headache. Clinical profile of the three groups of patients compared

\begin{tabular}{|c|c|c|c|c|c|c|}
\hline & \multirow[b]{2}{*}{ No } & \multicolumn{2}{|c|}{ Sex } & \multicolumn{2}{|c|}{ Age (ly ) } & \multirow{2}{*}{$\begin{array}{l}\text { Duration } \\
\text { of } H A \\
(\text { lr })\end{array}$} \\
\hline & & $M$ & $F$ & range & mean & \\
\hline Control & 35 & 16 & 19 & $23-52$ & 34 & - \\
\hline Migraine & 166 & 30 & 136 & $21-76$ & 39 & $1-42$ \\
\hline Tension & 95 & 52 & 43 & $16-81$ & 42 & $1-26$ \\
\hline
\end{tabular}

Table 3 Plasma serotonin in chronic tension headache. Plasma levels of serotonin (ng/10 platelets) of the three groups of patients investigated in this study.

\begin{tabular}{lll}
\hline & Range & Mean \\
\hline Control subjects & $125-872$ & 474 \\
Migraine h.a. free & $100-1620$ & 514 \\
$\quad$ headache & $70-1120$ & 384 \\
Tension headache & $92-823$ & $310^{*}$ \\
\hline
\end{tabular}

${ }^{*} \mathrm{p}=<0.001$ Analysis of variance Student-Newman-Keyls Procedure

and are of the same order as in migrainous patients during headache. Such observations appear to suggest that $\mathrm{CTH}$, like migraine, is a low serotonin syndrome. The low level of circulating serotonin reflects the low content of the amine in platelets. ${ }^{17}$

The loss of serotonin from platelets in migraine has been attributed to their activation in vivo during attacks of headache, which are associated with raised levels of beta-thromboglobulin (BTG) ${ }^{18}$ and platelet factor 4 (PT4), ${ }^{19}$ both of which are released by alpha granules, whilst serotonin itself is lost from dense bodies in association with ATP and calcium. Similar activation of platelets has been reported to occur in patients with $\mathrm{CTH},{ }^{20}$ in that, in addition to raised plasma BTG and PF4, the concentration of free plasma serotonin increases, almost certainly reflecting escape of serotonin from the platelet cell. Whilst in migraine, platelet activation and loss of serotonin are episodic, in the case of CTH these appear to be continuous.

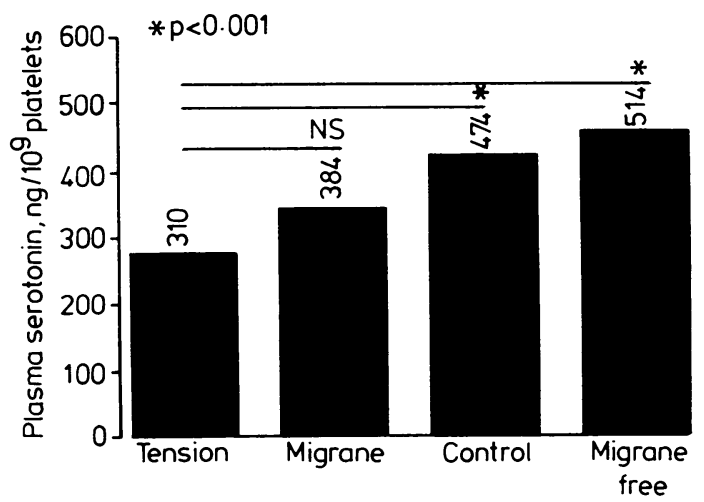

Fig Plasma serotonin in tension headache (Statistical comparison between groups) 
The low platelet serotonin in migraine almost certainly reflects reduced concentrations of the amine in other parts of the body, and in particular the brainstem, where its depletion leads to increased perception of nociceptive stimuli from various head and neck structures, and possibly leads to cranial vasodilatation. Such neural and vascular influences may produce headache through an interplay of mechanisms as suggested by Lance $e t$ al. ${ }^{14}$

In a recent study, ${ }^{21}$ serotonin uptake was found to be greater by platelets of patients with CTH than by those of migraineurs or normal controls, whilst mean platelet serotonin content (ng/10 $0^{9}$ platelets) was 533 in patients with CTH, 531 in normal controls and 332 in migraineurs. Unfortunately, there was no statement as to the frequency of headaches or whether headache was present at the time of collecting the specimens. In our own studies of serotonin metabolism in migraine, ${ }^{13}$ it was found that platelet serotonin content fell during headache, but incubation of platelets from headachefree and headache periods with excess serotonin, produced equal concentrations of the amine in both sets of platelets. It is therefore highly probable, that the increased uptake of serotonin by platelets of patients with CTH found in the study by Shukla et al, ${ }^{21}$ may in fact be an indication of the low initial serotonin content of the substance in the platelets of such patients. The authors' assumption that CTH is a high serotonin syndrome does not appear to be compatible with current concepts of serotonin physiology, namely peripheral vasoconstriction and central modulation of pain by closing the pain gate. ${ }^{17}$

On balance, the evidence available so far appears to favour the view that CTH resembles migraine biochemically, and can be regarded as one end of the spectrum of idiopathic headache, consisting of unremitting headache with a few, if any, migrainous characteristics, whilst the other end is made up of episodic headache with many associated features, the symptom-complex referred to as migraine.

The authors thank the Arthur Yenebis Foundation and the Prince Henry Hospital Research Fund for their generous financial support.

\section{References}

1 Bakal DA, Kaganov JA. Muscle contraction and migraine headache: psychological comparison. Headache 1977;17: 208-15.
2 Borgeat F, Hade B, Elie R, Larouche LM. Effects of voluntary muscle tension increases in tension headache. Headache 1984;24:199-202.

3 Haber JD, Kuczmierczyk AR, Adams HE. Tension headaches: muscle overactivity or psychogenic pain. Headache 1985;25:23-9.

4 Pikoff $\mathrm{H}$. Is the muscular model of headache still viable. A review of conflicting data. Headache 1984;24:186-98.

5 Featherstone HJ. Migraine and muscle contraction headaches: a continuum. Headache 1985;25:194-8.

6 Ziegler DK, Hassanein RS. Migraine, muscle contraction headache. Dichotomy studied by statistical analysis of headache symptoms. In: Rose FC, ed. Advances in Migraine Research and Therapy. New York: Raven Press, 1982:7-11.

7 Phillips $C$. The modification of tension headache pain using EMG biofeedback. Behav Res Ther 1977;15:119-29.

8 McArthur DL, Cohen J. Measures of forehead and finger temperature, frontalis EMG, heart rate and finger pulse amplitude during the between migraine headaches. Headache 1980;20:134-6.

9 Sicuteri F, Fanciullacci M, Michelacci S. Decentralization super- ڤ) sensitivity in headache and central panalgesia. In: Freedman AP, Graner ME, eds. Research and Clinical Studies in Headache. New York: Karger, 1978:19-38.

10 Onel Y, Friedman AP, Grossman JC. Muscle blood-flow studies in muscle contraction headache. Neurology 1961;11:935-9.

11 Martin PR, Mathews AM. Tension headache: psychophysiological investigation and treatment. $J$ Psychosomat Res 1978;22:389-99.

12 Krabbe AA, Olesen J. Headache provocation by continuous intravenous infusion of histamine. Clinical results and receptoo mechanisms. Pain 1980;8:253-9.

13 Anthony M, Lance JW. The role of serotonin in migraine. In Pearce J, ed. Modern Topics in Migraine. London: Heinemanf 1975:107-23.

14 Lance JW, Lambert GA, Goadsby PJ, Duckworth JW. Brainste influences on the cephalic circulation. Experimental data from cat and monkey of relevance to the mechanism of migraine Headache 1983;23:258-65.

15 Rolf LH, Wiele G, Brune GG. 5-Hydroxytryptamine in platelets. of patients with muscle contraction headache. Headac 1981;21:10-11.

16 Crawford N, Rudd RT. A spectrophotofluorometric method for the determination of serotonin in plasma. Clin Chim Acta 1962;7:114-21.

17 Douglas WW. Histamine and 5-hydroxytryptamine (serotonin and their antagonists). In: Gilman AG, Goodman LS, Gilman A, eds. Goodman and Gilman's The Pharmacological Basis of Therapeutic. New York: Macmillan, 1980:609-46.

18 Gawel M, Burkitt M, Rose FC. The platelet release reaction during migraine. Headache 1979;19:323-7.

19 D'Andrea G, Toed M, Cortelazzo S, Milone FF. Platelet activity in migraine. Headache 1982;22:207-12.

20 Takeshima T, Shimura T, Takahashi K. Platelet activation in muscle contraction headache and migraine. Cephalalgia 1987;7:239-43.

21 Shukla R, Shanker K, Nag M, Verma M, Bhargava KP. Serotonin in tension headache. $J$ Neuro Neurosurg Psychiatry 1987;50:1682-4.

22 Drummond PD, Lance JW. Clinical diagnosis and computed analysis of headache symptoms. J Neurol Neurosurg Psychiatry 1984;47:128-33. 